\title{
IL-4RA gene expression in PBMC with regard to place of living and atopy status
}

\author{
Hanna Danielewicz ${ }^{A-F}$, Anna Dębińska ${ }^{A-C, E, F}$, Anna Drabik-Chamerska ${ }^{B, C, E, F}$, Danuta Kalita ${ }^{B, C, E, F}$, Andrzej Boznański ${ }^{A-C, E, F}$ \\ ${ }^{\text {st }}$ Department and Clinic of Pediatrics, Allergy and Cardiology, Wroclaw Medical University, Poland \\ A - research concept and design; B - collection and/or assembly of data; $C$ - data analysis and interpretation; \\ $D$ - writing the article; $E$ - critical revision of the article; $F$ - final approval of the article
}

Address for correspondence

Hanna Danielewicz

E-mail: hanna.danielewicz@umed.wroc.pl

\section{Funding sources}

This study was supported by statutory funds of the Department of Pediatrics, Allergy and Cardiology, Wroclaw Medical University, Poland, received from the Ministry of Science and Higher Education.

Conflict of interest

None declared

Received on July 23, 2016

Reviewed on September 28, 2016

Accepted on December 15, 2016

\begin{abstract}
Background. IL-4 and IL-4RA are key factors in allergic inflammation. IL-4 stimulates both IgE production and Th2 lymphocyte differentiation. Increased levels of IL-4 and IL-4RA have been shown in allergic patients. Genetic analyses have confirmed that polymorphisms within the IL-4RA gene influence the risk of allergy and can change the expression of the protein. Due to gene-environment interactions, this process is also likely to be modified by environmental exposure.
\end{abstract}

Objectives. The aim of the study was to evaluate the /L-4RA gene expression in peripheral blood mononuclear cells (PBMC) from atopic and non-atopic subjects with regard to place of living (urban vs rural).

Material and methods. We enrolled 38 subjects into the study, 18 of whom were atopic. Atopy was estimated according to the results of a skin prick test. PBMC were isolated from whole blood, total RNA was extracted and reverse transcribed into cDNA. We performed real-time PCR to measure gene expression, the ACTB gene was chosen as a reference and the delta-delta $\mathrm{Ct}(\triangle \Delta C T)$ method was applied for relative quantification. The Mann-Whitney U test was used for statistics.

Results. We did not observe any statistically significant differences in the gene expression profile between atopic and non-atopic subjects regardless of their place of living. However, a trend was observed for atopic rural inhabitants to have lower levels of IL-4RA gene expression than atopic subjects living in the town.

Conclusions. The regulation of $L-4 R A$ gene expression is complex and probably influenced by both genetic and environmental factors, such as farming exposures, which could provide the counterbalance to atopy.

Key words: gene expression, asthma, atopy, IL-4RA

DOI

10.17219/acem/ 67787

\section{Copyright}

Copyright by Author(s)

This is an article distributed under the terms of the

Creative Commons Attribution Non-Commercial License

(http://creativecommons.org/licenses/by-nc-nd/4.0/) 
Atopy, regarded as a susceptibility to react with IgE to common allergens, is a complex trait involving gene-environment interactions. Even though the genetic background seems to be obvious due to family inheritance of atopic disorders such as asthma or allergic rhinitis, recent genetic studies using genecandidate and Genome Wide Association Study (GWAS) approaches have not provided a simple solution for disease susceptibility. We know much more about the pathogenesis owing to these studies, but there is still "a missing heritability", and the genetic effect associated with a single nucleotide polymorphism (SNP) or gene seems to be of minor importance. Environmental factors influence genes changing their expression pattern by silencing or activating specific pathways, and this process is crucial as a disease trigger. ${ }^{1}$

In recent years, there have been several studies in which the expression profile was estimated in relation to atopy or asthma. As an example, global gene expression studies in asthma have been performed in peripheral blood mononuclear cells (PBMC), bronchial biopsy specimens and epithelial cells from nasal lavage. ${ }^{2-4}$

This genetic profiling could be used as a new marker of atopic disorders or an indicator of disease severity. In that context, transcriptomic profiles of airway smooth muscle cells have been used for distinguishing atopic asthma subjects from atopic patients without asthma. ${ }^{5}$ The cap analysis of gene expression (CAGE) method has been performed in children with asthma (study sample $\mathrm{n}=37$ ) to reveal that in subjects with severe asthma, 1305 transcription start sites and 816 known genes are differentially expressed. ${ }^{6}$ Further, epithelial gene expression patterns have been pursued to differentiate atopic children from healthy controls (study sample $n=45)^{7}$

Both atopy per se and atopic disorders, are associated with increased Th2 cell activity. This is characterized by excessive production of IgE in response to different antigens. IL-4 is the key cytokine in IgE-dependent reactions, as it activates Th2 differentiation and directs the immunoglobulin production to generate IgE from IgM. Together with IL-13, IL-4 is also responsible for increasing mucus production and remodeling in asthma. IL-4 exerts its function by binding to IL-4RA, which is the common receptor for both IL-4 and IL-13. The signal is transmitted by activation of Janus kinase (JAK) and phosphorylation of STAT6. ${ }^{8}$

Increased expression of the $I L-4 R A$ gene has been revealed in only a few studies regarding different atopic phenotypes. One example is the recent research that showed that transfectants carrying SNP within the FCER2 gene (rs2228137), which is associated with severe asthma, presented higher expression of the $I L-4 R A$ gene after stimulation with CD23. This phenomenon was related strictly to $I L-4 R A$, and did not affect the gene expression of $I L-1 A$, $I L-2, I L-4$, TNFA or IL8. ${ }^{9}$ Two further studies were done in patients with asthma with the same result. ${ }^{10,11}$

The $I L-4 R A$ gene has long been considered a good candidate for the asthma and atopy susceptibility gene. In different types of studies - linkage analysis, gene-candidate studies and GWAS - its role has been proven. ${ }^{12,13}$ The gene is highly polymorphic. The majority of SNPs are inherited in blocks. The most relevant are present in exon 12 (E375A, S411L, S478P, and Q551R), 1 identified in the promoter (C3223T), and 1 coding for amino acid changes in the extracellular portion of the receptor (I50V). SNPs within the $I L-4 R A$ gene have been described as associated with severe asthma exacerbations, lower lung function, and increased mast-cell-related tissue inflammation. ${ }^{14}$ Cells presenting different forms of IL-4RA (I50 or V50) have been shown as presenting an altered phosphorylation pattern of STAT6 during IL-4 stimulation, thus affecting IL-4RA function. ${ }^{8}$ Previously, we have demonstrated the effect of C3223T polymorphism within the promoter of the $I L-4 R A$ gene and 150 on atopy susceptibility. ${ }^{15}$ These polymorphisms are also associated with a decreased level of soluble IL-4R. ${ }^{16}$

Here we report the difference in $I L-4 R A$ gene expression with regard to atopy status and place of living (urban vs rural).

\section{Material and methods}

In the study, we enrolled 38 subjects attending an allergy outpatient or inpatient clinic, 18 of whom were atopic. Atopy was estimated according to the results of a skin prick test to common allergens (dust mites - Dermatophagoides pteronyssinus, Dermatophagoides farinae - cat, dog, birch, mix of grasses) with at least 1 positive result of $\geq 3 \mathrm{~mm}$. Control subjects had a negative skin prick test result. The procedure was performed according to the European Academy of Allergy and Clinical Immunology standards. Venous blood samples were taken into ethylenediaminetetraacetic acid (EDTA) probes (SARSTEDT AG \& Co., Nümbrecht, Germany). PBMC were isolated from whole blood using the gradient method. We extracted total RNA using the QIAamp DNA Blood Mini Kit (Qiagen Inc., Valencia, USA) according to the manufacturer's protocol. Reverse transcription to cDNA was carried out using the First Strand DNA Reverse Transcription Kit (Roche Ltd., Basel, Switzerland) according to the manufacturer's protocol. We performed real-time PCR for gene expression using LightCycler 1.5 with specific hybridization probes (Universal ProbeLibrary, Roche, Basel, Switzerland) and LightCycler TaqMan Master Mix (Roche) according to the manufacturer's protocol. We chose the $A C T B$ gene as a reference gene. Delta $\mathrm{Ct}(\Delta \mathrm{CT})$ and delta-delta $\mathrm{Ct}(\Delta \Delta \mathrm{CT})$ values were determined $(\triangle \mathrm{CT}=\mathrm{Ct}$ GENE $-\mathrm{Ct} \mathrm{ACTB})$ for relative quantification and $2^{\wedge}-\Delta \Delta C T$ for the related fold change estimation. The Mann-Whitney $U$ test was used for statistics to compare $\Delta C T$ between the groups. The study was approved by the Ethics Committee of Wroclaw Medical University, Poland. All participants signed an informed consent. 


\section{Results}

The characteristics of the study group are presented in Table 1. The group consisted of children and adults. The expression level of $I L-4 R A$ in children vs adults did not differ significantly. Four subjects skipped the skin prick tests, so the atopy status was not estimated.

We did not observe statistically significant differences in $I L-4 R A$ expression within the groups ( $>0.05)$. Atopic subjects had slightly higher $I L-4 R A$ gene expression levels than non-atopic subjects (Fig. 1). When comparing gene expression according to the place of living (urban vs rural), a trend was observed for rural dwellers to have lower gene expression levels of the $I L-4 R A$ than their urban counterparts. The urban inhabitancy was a similar stimulator for $I L-4 R$ expression and atopy $\left(2^{\wedge}-\Delta \Delta C T 2.07\right.$ vs 2.0139$)$ (Fig. 2). This phenomenon was more pronounced in atopic subjects (urban vs rural $2^{\wedge}-\Delta \Delta$ CT 2.75) (Fig. 3).

Table 1. Characteristics of study group

\begin{tabular}{|l|c|c|}
\hline \multirow{3}{*}{ Parameter } & Control $(\mathrm{n}=16)$ & Atopic $(\mathrm{n}=18)$ \\
\hline \multirow{3}{*}{ Age } & mean $14.84 \pm 12.1$ & mean $11.55 \pm 7.42$ \\
& $\min 1.5$ & $\min 3$ \\
& $\max 47$ & $\max 36$ \\
Sex & median 10.5 (7.5-18.5) & median 11.5 (6-14) \\
& males 5 & males 7 \\
Place of living & females 11 & females 11 \\
& village 4 & village 5 \\
& town 12 & town 13 \\
\hline
\end{tabular}

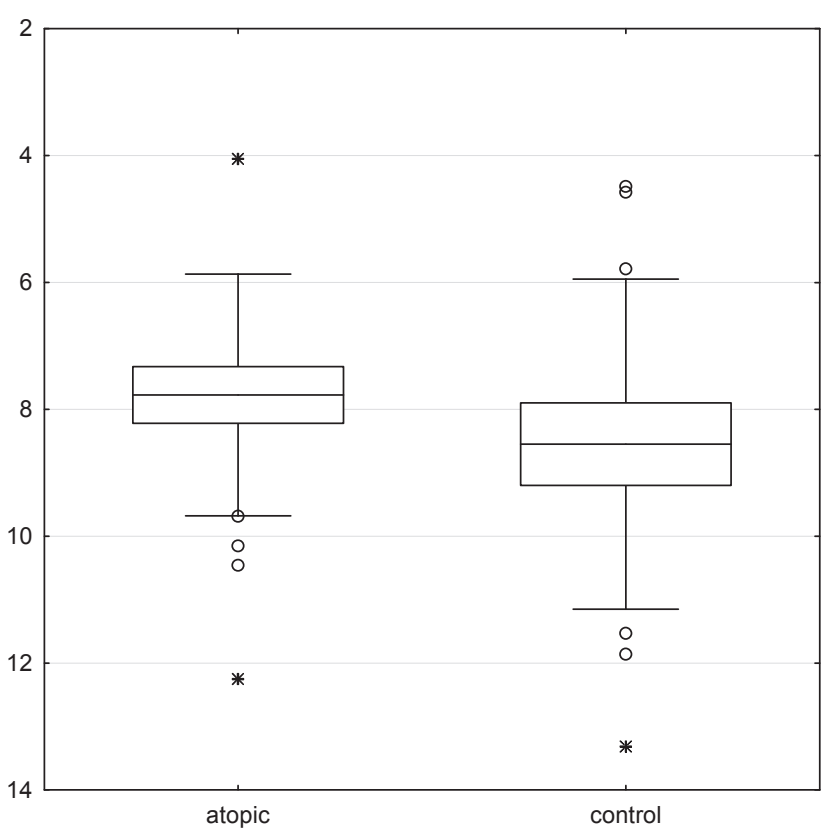

Fig. 1. IL-4RA gene expression in PBMC in atopic vs control subjects

Gene expression of the IL-4RA gene was expressed as $\triangle C T$, where $\triangle C T=C t I L-4 R A-C t A C T B$ for each sample; the lower the $\triangle C$ t values, the greater the amount of gene expression; the $\mathrm{Y}$-axis has been reversed to better illustrate the effect; data is given as mean \pm SE and \pm SD; fold change $2 \wedge-\triangle \triangle C T=2.0139$

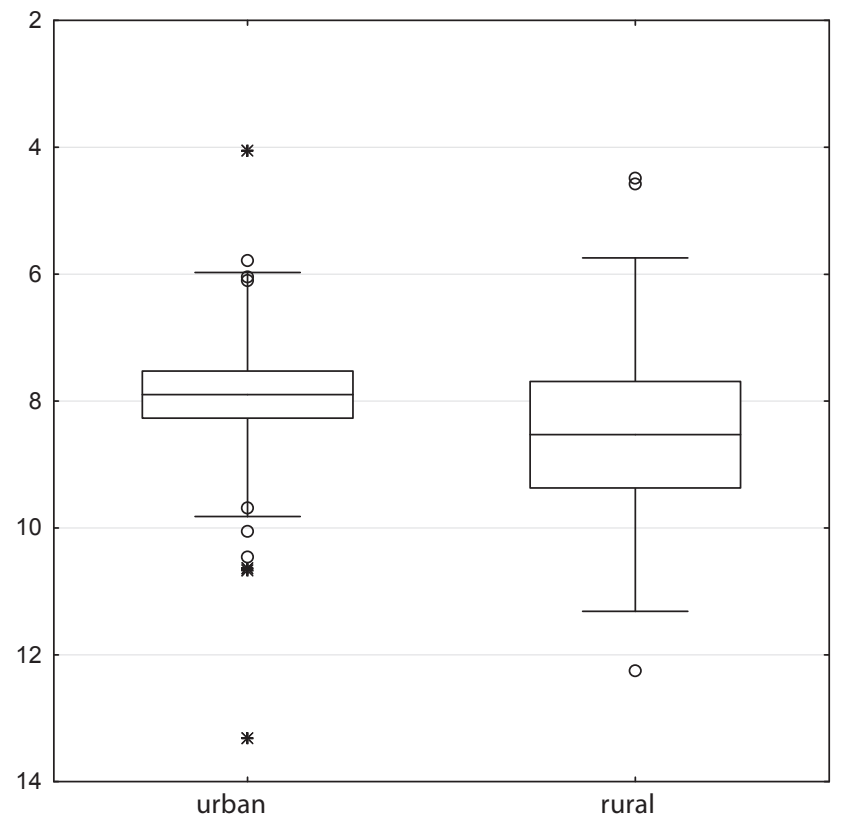

Fig. 2. IL-4RA gene expression in PBMC in urban vs rural subjects

Gene expression of the IL-4RA gene was expressed as $\triangle C T$, where $\triangle C T C=C t$ IL-4RA - Ct ACTB for each sample; the lower the $\triangle C t$ values, the greater the amount of gene expression; the $Y$-axis has been reversed to better illustrate the effect; data is given as mean \pm SE and \pm SD; fold change $2^{\wedge}-\triangle \triangle C T=2.07$.

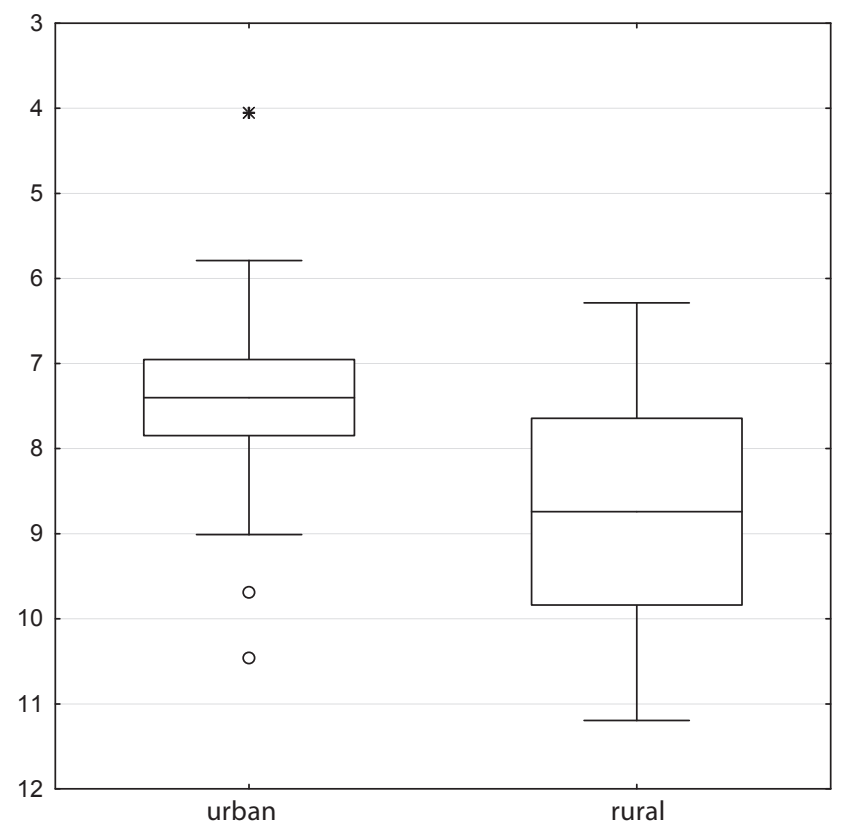

Fig. 3. IL-4RA gene expression expressed as $\triangle C T$ in atopic subjects living in urban vs rural environment

Gene expression of the IL-4RA was expressed as $\triangle C T$, where $\Delta C T=C t$ IL-4RA - Ct ACTB for each sample; the lower the $\triangle C$ t values, the greater the amount of gene expression; the $Y$-axis has been reversed to better illustrate the effect; data is given as mean \pm SE and \pm SD; fold change $2 \wedge-\triangle \triangle C T=2.75$. 


\section{Discussion}

In this study, we report that $I L-4 R A$ gene expression did not differ significantly in terms of atopy and place of living (urban vs rural). Only slight differences were observed for atopic and urban subjects to have higher $I L-4 R A$ expression. Most interestingly, atopic subjects living in rural settings tend to have lower $I L-4 R A$ gene expression in comparison to atopic subjects living in urban ones. In relation to that fact, it could be presumed that the expression of $I L-4 R A$ is regulated by both atopy and environmental factors. What is more, farming exposures associated with the rural environment seem to be a protective factor, corresponding with lower levels of $I L-4 R A$ expression.

$I L-4 R A$ gene expression has been studied in several genome-wide expression analyses as one of the components; however, there were only a few studies focused specifically on $I L-4 R A$ expression. In 2014, Pascual et al. performed genome-wide expression profiling of B lymphocytes and revealed the IL-4RA protein-coded transcript was one of the most differentially expressed transcriptomes of the $B$ cells between the group of patients with allergic asthma and the controls. ${ }^{10}$ These results were further validated within the relative expression analysis of $I L-4 R A$ in CD19+ $B$ cells from 10 subjects and PBMC from 25 subjects. It has also been shown recently that decreased expression of $I L-4 R A$ in B cells is observed during anti-IgE biological treatment for severe asthma. ${ }^{11}$ Some evidence of the environmental interaction with $I L-4 R A$ gene expression was provided by a study conducted in the Republic of Karelia in 2014, which showed that the maternal genetic variants in IL-4/IL-13 pathway genes, among them IL-4R Ile50Val, influenced IgE levels in school children, independently of the children's genetic effects. These effects differed in "Western or Eastern" environments (Finnish and Russian Karelian populations). These alternations could be explained by the epigenetic mechanism related to both the genetic background of the mother and environmental exposures in the prenatal period. ${ }^{17}$

Environment exposures associated with farming have been proposed as protective against atopy and this relation was proved in several studies. However, it has been shown that different farm exposures have different effects on the expression of genes related to innate immunity, i.e., tolllike receptors, possibly highly tied with early development of the atopic phenotype. ${ }^{18}$ One of these exposures - raw milk consumption in the first year of life - was shown to change the expression of these genes in farm children. ${ }^{19}$ Another study found that in farm children there was an increase in gene expression of IRAK-4 and RIPK1, and innate regulatory modules, such as SOCS4, IL10 and TGFB, as well as lower expression of $I F N-\gamma$ and $I L-4$ and higher of Th2-associated molecules, such as GATA3. However, the authors were not able to associate these differences with atopic conditions. These findings provide arguments that the molecular basis of allergic disorders possibly cannot be explained by the Th2 paradigm alone. ${ }^{20}$ There are also studies in which farming is indicated as a risk factor for different conditions associated with the respiratory system, particularly on large farms. ${ }^{21}$ Others conclude that the protective effects, seen as the altering gene expression of innate immunity, depend on the specificity of farm exposure. $^{20}$

The IL-4 receptor has recently been proposed as a therapeutic target for asthma and atopic dermatitis. ${ }^{22}$ Hamilton et al. observed in patients with atopic dermatitis that the transcriptome profile and disease severity changed during the treatment with dupilumab, which is human $\mathrm{mAb}$ directed at IL-4RA. ${ }^{23}$ Specifically, in the skin biopsy specimens, the change before and after treatment was related to the suppression of immune and epidermal response, but no change in IL, IL13, IL5, and IL31 was observed. Dupilumab treatment was also used in uncontrolled persistent asthma as add-on therapy in a phase IIb clinical trial. It was effective for both FEV1 improvement and decrease of exacerbation rate. ${ }^{24}$ Bechert et al. also described anti-IL-4RA effectiveness in the therapy of nasal polyps refractory to $\mathrm{GKSs}{ }^{25}$

The question arises about the exact role of IL-4. Is it simply an atopy cytokine? After all, IL-4 also regulates the response to parasites. ${ }^{26}$ The cord blood CD34+ progenitor cell response to LPS, which is a component of the bacterial wall, is dependent on IL-4. IL-4 but not IL-13 reduces cord blood progenitor cell Eo/B differentiation in response to LPS and this process is dependent on IL-4R signaling. ${ }^{27}$ Simple allergy triggering seems not the only action taken by IL-4. There are studies in cancer in which the expression of IL-4 pathway genes was shown to change depending on disease status. ${ }^{28}$ IL- 4 is also fundamental for cognition and brain function. In mice, the performance of learning and memory tasks is dependent on an increase of $\mathrm{T}$ cells in the meninges, producing cytokines such as IL-4. Mice lacking $\mathrm{T}$ cells exhibit cognitive impairment. ${ }^{29} \mathrm{IL}-4$ can also counterbalance the aging process in the brain and could possibly play a role in Alzheimer's disease. ${ }^{30}$

The effect of IL-4 could depend on the specificity of the tissue and local environment. In a mouse model of asthma, IL-4 function depends on the cell type producing this cytokine. Both IL-4 and IL-13 are produced by T cells and a variety of cell types of the innate immune system. IL-4/ IL-13 derived from the innate immune cells are responsible for the Th2 response in lungs and intestines, and protect against parasite Nippostrongylus brasiliensis. On the other hand, IL-4/IL-13 from T cells are critical for the induction of allergic inflammation and bronchial hyperresponsiveness, with IgG1 and IgE production, eosinophil and basophil recruitment to the lungs, goblet cell hyperplasia, expression of Muc5ac, Clca3, RELM- $\beta$, and the differentiation of alternatively activated macrophages. ${ }^{31}$ 


\section{Conclusions}

The regulation of $I L-4 R A$ gene expression is complex and probably influenced by both genetic - specific polymorphism - and environmental factors, such as farming exposures, which could provide a counterbalance to atopy.

\section{References}

1. Vaillancourt VT, Bordeleau M, Laviolette M, Laprise C. From expression pattern to genetic association in asthma and asthma-related phenotypes. BMC Res Notes. 2012;(13)5:630.

2. Baines KJ, Simpson JL, Bowden NA, Scott RJ, Gibson PG. Differential gene expression and cytokine production from neutrophils in asthma phenotypes. Eur Respir J. 2010;35:522-531.

3. Bjornsdottir US, Holgate ST, Reddy PS, et al. Pathways activated during human asthma exacerbation as revealed by gene expression patterns in blood. PLoS One. 2011;6:e21902.

4. Chen E, Miller GE, Walker HA, Arevalo JM, Sung CY, Cole SW. Genomewide transcriptional profiling linked to social class in asthma. Thorax. 2009;64(1):38-43.

5. Yick $C Y$, Zwinderman $A H$, Kunst $P W$, et al. Gene expression profiling of laser microdissected airway smooth muscle tissue in asthma and atopy. Allergy. 2014;69(9):1233-1240.

6. Persson H, Kwon AT, Ramilowski JA, et al. Transcriptome analysis of controlled and therapy-resistant childhood asthma reveals distinct gene expression profiles. JAllergy Clin Immunol. 2015;136(3):638-648.

7. Giovannini-Chami L, Marcet B, Moreilhon C, et al. Distinct epithelial gene expression phenotypes in childhood respiratory allergy. Eur Respir J. 2012;39(5):1197-1205.

8. Ford AQ, Heller NM, Stephenson L, Boothby MR, Keegan AD. An atopy-associated polymorphism in the ectodomain of the IL-4R(alpha) chain (V50) regulates the persistence of STAT6 phosphorylation. J Immunol. 2009;183(3):1607-1616.

9. Chan MA, Gigliotti NM, Meng J, Rosenwasser LJ. Asthma-related SNP in FCER2 is associated with increased expression of IL-4R on human B cells. Int J Immunogenet. 2011;38(6):533-538.

10. Pascual M, Roa S, García-Sánchez A, et al. Genome-wide expression profiling of $B$ lymphocytes reveals IL4R increase in allergic asthma. J Allergy Clin Immunol. 2014;134(4):972-975.

11. Chan MA, Gigliotti NM, Dotson AL, Rosenwasser LJ. Omalizumab may decrease IgE synthesis by targeting membrane IgE1 human B cells. Clin Transl Allergy. 2013;3(1):29.

12. Rogers AJ, Raby BA, Lasky-Su JA, et al. Assessing the reproducibility of asthma candidate gene associations using genome-wide data. Am J Respir Crit Care Med. 2009;179(12):1084-1090.

13. Loza MJ, Chang BL. Association between Q551R IL4R genetic variants and atopic asthma risk demonstrated by meta-analysis. J Allergy Clin Immunol. 2007;120(3):578-585.

14. Wenzel SE, Balzar S, Ampleford E, et al. IL4R alpha mutations are associated with asthma exacerbations and mast cell//gE expression. Am J Respir Crit Care Med. 2007;175(6):570-576.
15. Danielewicz H, Hurkacz M, Boznański A, Wiela-Hojeńska A. Polymorphism in the promoter and coding region of the IL-4 receptor alphachain gene in atopic children. Adv Clin Exp Med. 2007;16(6):735-741.

16. Danielewicz H, Hurkacz M, Boznański A, Wiela-Hojeńska A, Chamerska-Drabik A. Association of soluble IL-4R serum levels and IL-4R a chain gene polymorphisms. Adv Clin Exp Med. 2009;18(6):559-565.

17. Zhang G, Khoo SK, Mäkelä MJ, et al. Maternal genetic variants of IL4/ IL13 pathway genes on IgE with "Western or Eastern environments/ lifestyles". Allergy Asthma Immunol Res. 2014;6(4):350-356.

18. Ege MJ, Frei R, Bieli $C$, et al. Not all farming environments protect against the development of asthma and wheeze in children. J Allergy Clin Immunol. 2007;119(5):1140-1147.

19. Loss G, Bitter S, Wohlgensinger J, et al. Prenatal and early-life exposures alter expression of innate immunity genes: The PASTURE cohort study. J Allergy Clin Immunol. 2012;130(2):523-530.

20. Frei R, Roduit $C$, Bieli $C$, et al. Expression of genes related to antiinflammatory pathways are modified among farmers' children. PLoS One. 2014;9(3):e91097.

21. Poole JA. Farming-associated environmental exposures and effect on atopic diseases. Ann Allergy Asthma Immunol. 2012;109(2):93-98.

22. Boguniewicz M, Leung DY. Targeted therapy for allergic diseases: At the intersection of cutting-edge science and clinical practice. J Allergy Clin Immunol. 2015;135(2):354-356.

23. Hamilton JD, Suárez-Fariñas M, Dhingra N, et al. Dupilumab improves the molecular signature in skin of patients with moderate-to-severe atopic dermatitis. J Allergy Clin Immunol. 2014;134(6):1293-1300.

24. Wenzel S, Castro M, Corren J, et al. Dupilumab efficacy and safety in adults with uncontrolled persistent asthma despite use of mediumto-high-dose inhaled corticosteroids plus a long-acting $\beta(2)$ agonist: A randomised double-blind placebo-controlled pivotal phase 2b dose-ranging trial. Lancet. 2016;388(10039):31-44. doi:10.1016/ S0140-6736(16)30307-5 [Ahead of print]

25. Bachert C, Mannent L, Naclerio RM, et al. Effect of subcutaneous Dupilumab on nasal polyp burden in patients with chronic sinusitis and nasal polyposis: A randomized clinical trial. JAMA. 2016;315(5): 469-479.

26. Chatterjee S, Clark CE, Lugli E, Roederer M, Nutman TB. Filarial infection modulates the immune response to Mycobacterium tuberculosis through expansion of CD4+ IL-4 memory T cells. J Immunol. 2015;194(6):2706-2714.

27. Reece P, Gauvreau GM, Sehmi R, Denburg JA. IL-4 and IL-13 differentially regulate TLR-induced eosinophil-basophil differentiation of cord blood CD34+ progenitor cells. PLoS One. 2014;9(6):e100734.

28. Bankaitis KV, Fingleton B. Targeting IL4/IL4R for the treatment of epithelial cancer metastasis. Clin Exp Metastasis. 2015;32(8):847-856.

29. Derecki NC, Cardani AN, Yang CH, et al. Regulation of learning and memory by meningeal immunity: a key role for IL-4. J Exp Med. 2010;207(5):1067-1080. doi:10.1084/jem.20091419

30. Gadani SP, Cronk JC, Norris GT, Kipnis J. IL-4 in the brain: A cytokine to remember. J Immunol. 2012;189(9):4213-4219.

31. Oeser K, Maxeiner J, Symowski C, Stassen M, Voehringer D. T cells are the critical source of IL-4/IL-13 in a mouse model of allergic asthma. Allergy. 2015;70(11):1440-1449. 